\title{
Comparison of Chiral Separation on Amylose and Cellulose Tris(3,5-dimethylphenylcarbamate)-Coated Zirconia in HPLC
}

\author{
In Whan Kim,a Jong Kwon Ryu, , Sung Duck Ahn,, Jung Hag Park, ${ }^{\text {b, }}{ }^{\text {K }}$ Kwang-Pill Lee, Jae Jeong Ryoo, \\ Myung Ho Hyun, ${ }^{d}$ Yoshio Okamoto, ${ }^{e}$ Chiyo Yamamoto, ${ }^{e}$ and Peter W. Carr ${ }^{f}$ \\ "Dept. of Chemical Education, Taegu Cniversity, Gyeongsan 712-714. Korea \\ ${ }^{5}$ Dept. of Chemistry, Yeumgnam Universin, Gveongsan 712-749. Korea \\ 'Dept. of Chemical Education, Kumgpook National Chiversin, Daegu 702-701. Korea \\ 'Dept. of Chemistry, Pusan National Cniversin, Busan 609-735. Korea \\ 'Dept of Applied Chemistry, Graduate School of Engineering, Nagova Chiversin, Nagova $46+-8603$, Japan \\ Dept of Chemistry, University of Minnesota MN 55455. CSA \\ Received Atugust 2. 2002
}

Key Words : Chiral stationary phase. Amylose and cellulose tris(3,5-dimethylphenỵlcarbamate). Zirconia. HPLC

HPLC separation method based on chiral stationary phases (CSPs) has become one of the most attractive approaches to chiral separations. due to their simplicity for determining optical purity and easy extension to the semipreparative and preparative scales. ${ }^{3}$ One of the major problems in using many CSPs is their narrow range of analyte applicability; they can only discriminate a linited number of specific types of chemical entities. and it is frequently necessary to derivatize the compounds of interest to achieve separation. ${ }^{2}$ Ont the other hand. the polysaccharide derivative-based CSPs developed by Okamoto and co-workers ${ }^{3-6}$ have proven to be highly versatile and rugged. Okamoto reported the resolution of $64 \%$ of 483 racentic mixtures on cellulose tris(3.5-dimethylphenyl carbamate) (CDMPC) and $80 \%$ were successfully resolved on either the cellulose or the corresponding anylose carbamate (ADMPC).

Fast method development, high efficiency, rapid resolution of enantiomers, and robustness are the main criteria for chiral separation methods, especially in the pharmacentical industry. These priorities require stable CSPs capable of achieving baseline separations in the minimum time, which ultimately means high selectivity and efficiency. Silica is the most popular choice for support for HPLC stationary phase ligands due to the mechanical strength, wide range of particle and pore dimensions. pore structure and well-established silane chemistry. However, silica and bonded phase ligands have stability problents. Silica dissolves in mobile phase buffered at or above $\mathrm{pH} 8$ with loss of bonded phase ligand and colunn packing. ${ }^{8}$ Loss of organosilanes from the silica surface via hydrolysis proceeds rapidly at low $\mathrm{pH}(<3)$ and at higher temperature $\left(40^{\circ} \mathrm{C}\right)$. These deficiencies of the column packing create problems of poor injection reproducibility. poor peak shape, and high backpressure. thus making method development tasks difficult. Over the last decade. zirconia has received considerable attention as a stationary phase support for HPLC. ${ }^{9,1 i}$ Zirconia particles are very

${ }^{*}$ Corresponding author. E-mail: jhparkiạyu.ac.kr robust material; they show no detectable signs of dissolution over the $\mathrm{pH}$ range from $\mathrm{I}$ to 14 and have been used for prolonged periods at temperatures up to $200^{\circ} \mathrm{C}$ in chromatographic separations. We recently reported preparation of zirconia based CSPs with cellulose, bovine serum albumin and $\beta$-cyclodextrin for use in either normal or reversedphase LC separation of cliral compounds. ${ }^{11 \cdot 14}$

In this work we compared chromatographic performances of chiral separation for ADMPC and CDMPC coated on 3 . $\mu \mathrm{m}$ zirconia particles by measuring retention of a set of racemic compounds on them. We used narrow-bore ( $1-\mathrm{mm}$ ID) columns that lead to many advantages such as low consumption of both mobile and stationary phases etc. ${ }^{15-17}$

\section{Experimental Section}

Reagents and materials. All reagents used for the preparation of the stationary phase were reagent grade or better Microcrystalline cellulose and amylose were purchased from Nakarai Chemicals (Japan). 3,5-Dimethylphenyl isocyanate, $\mathrm{N}, \mathrm{N}$-dimethylacetamide and pyridine were obtained from Aldrich (Milwaukee. USA). Zirconia, having a mean pore size of $30 \mathrm{rm}$ and a mean particle diameter of $3 \mu \mathrm{m}$, was obtained from ZirClurom Separations (Anoka. USA). Acetone, and 2-propanol were HPLC grade (J.T. Baker. Phillipsburg. USA), $n$-Hexane and tetrahy drofuran (THF) were purchased from EM Sciences (Gibbstown, USA). The racemic compounds studied are shown in Figure 1. All are commercially available. Solutions at a concentration of $0.1 \mathrm{mg} / \mathrm{mL}$ were prepared by dissolving the compounds in the mobile phase.

Preparation of CDMPC and ADMPC. CDMPC and ADMPC were synthesized as previously reported ${ }^{5.18}$ and were characterized by elemental analyses, IR and NMR spectroscopy. The data indicated that hydroxyl groups of cellulose and anylose were almost completely converted to the corresponding carbamate groups.

Preparation of CDMPC and ADMPC coated zirconia. To dehydroxylate zirconia's surface. the particles were 


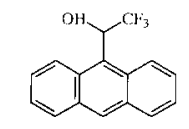

Trifluoroanthryl ethanol

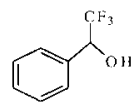

$\alpha$-(Trifluoromethyl) benzyl alcohol<smiles>CC(CCO)c1ccccc1</smiles>

3-Phenyl-1-butanol 6

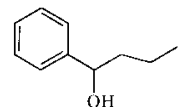

1-Phenyl-1-butanol

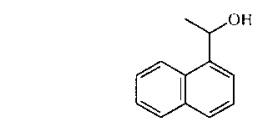

$\alpha$-Methyl-1-naphthalene methanol 3

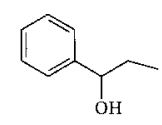

1-Phenyl-1-propanol 4

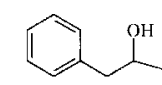

1-Phenyl-2-propanol 5

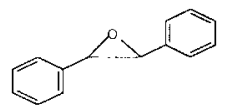

trans-Stilbene oxide

10

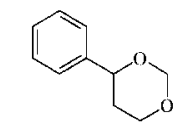

4-Phenyl-1,3-dioxane 11<smiles>O=C1CCC(c2ccccc2)O1</smiles>

$\gamma$-Phenyl- $\gamma$-butyrolactone 12

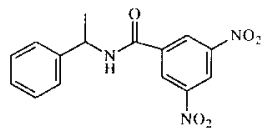

(3,5-Dinitrobenzoyl)- $\alpha$ methylbenzylamine<smiles>O=C1CCC(c2ccc3ccccc3c2)O1</smiles>

$\gamma$-(2-Naphthyl)- $\gamma$-butyrolactone 13<smiles>CC(C#N)c1ccccc1</smiles>

$\alpha$-Methylbenzyl cyanide 14

Figure 1. Structures of racemic compounds.

heated at $750^{\circ} \mathrm{C}$ for $5 \mathrm{~h}$ and cooled over phosphorus pentoxide before use. Typically, $1.0 \mathrm{~g}$ of particles was suspended in $10 \mathrm{~mL}$ of THF and sonicated under vacuum for $15 \mathrm{~min}$ to eliminate the air from the pores. Polymer loading of $4 \%$ by weight was chosen since this loading has been shown to offer excellent chiral recognition ability and colunn efficiency. ${ }^{11,13}$ The corresponding amount of CDMPC or ADMPC was dissolved in $10 \mathrm{~mL}$ of THF and the solution was added to the slurry of zirconia in THF using a syringe punp at a rate of $0.04 \mathrm{~mL} / \mathrm{min}(\sim 4 \mathrm{~h})$. The suspension was stirred ovennight and then the solvent was slowly removed by rotary evaporation at room temperature. Finally, the particles were dried in vacuum at $50^{\circ} \mathrm{C}$.

Chromatography. Packing materials were suspended in a (1:1) hexane/2-propanol mixture and packed into $25 \mathrm{~cm} \times$ $1 \mathrm{~mm}$ (ID) columus using the downward slurry method at ca. 7000 psi. 2-Propanol was employed as the displacing solvent. A chromatographic system consisting of a Model 7520 injector with a $0.5-\mu \mathrm{L}$ intenal loop (Rheodyne, CA, USA), a Model 530 column oven (Altech. IL, USA) set at $30^{\circ} \mathrm{C}$ and a Linear Model 200 UV/VIS detector (Alltech. IL, USA) with a $0.25-\mu \mathrm{L}$ flowcell set at $254 \mathrm{~nm}$ was used. A Hew lett-Packard (Avondale, CA. USA) Series 3365 integrating recorder was used to record chromatograms. The mobile phases were mixtures of 2-propanol and hexane (2/98 or $10 / 90 \mathrm{v} / \mathrm{\%} \%$ ). They were filtered through a membrane filter of $0.5-\mu \mathrm{m}$ pore size and degassed prior to use. The flow rate was $200 \mu \mathrm{L} / \mathrm{min}$. The dead time was estimated by using 1.3,5-tri-tent-butylbenzene as unretained compound. ${ }^{19}$

\section{Results and Discussion}

The performance of a column packed with ADMPC and CDMPC-zirconia is shown for the resolution of trifluoro-
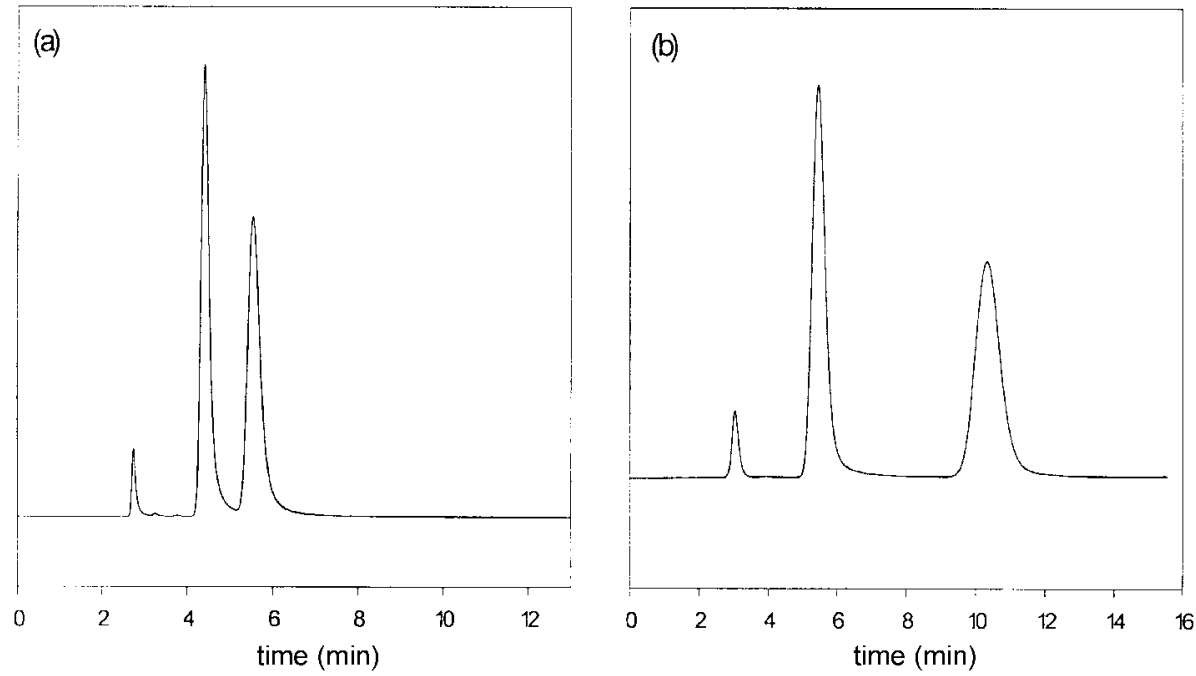

Figure 2. Chromatograms for the separation of racemic trifluoroanthryl ethanol on (a) ADMPC- and (b) CDMPC-zirconia. Columul dimension; $25 \times 0.1 \mathrm{~cm}$ I.D. Mobile phase; $90: 10(\mathrm{v} / \mathrm{v} \%)$ n-hexane: 2-propanol. Flow rate; $0.2 \mathrm{~mL} / \mathrm{min}$. Column temperature; 25 "C. 
Table 1. Chromatographic Data on ADMPC- and CDMPC-Zirconia in Hexane/2-propanol

\begin{tabular}{clrccc}
\hline \multirow{2}{*}{$\begin{array}{c}\text { Compound } \\
\text { No. }\end{array}$} & $\begin{array}{c}\text { Mobile Phase } \\
(v / v \%)\end{array}$ & \multicolumn{2}{c}{ ADMPC } & \multicolumn{2}{c}{ CDMPC } \\
\cline { 3 - 6 } & \multicolumn{1}{c}{$k_{1}{ }^{a}$} & $\alpha^{b}$ & $k_{1}{ }^{a}$ & $\alpha^{b}$ \\
\hline 1 & $90: 10$ & 0.86 & 1.55 & 0.89 & 2.75 \\
2 & $98: 2$ & 9.55 & 1.00 & 9.24 & 1.10 \\
3 & $98: 2$ & 8.97 & 1.08 & 0.87 & 1.86 \\
4 & $98: 2$ & 3.20 & 1.06 & 2.80 & 1.18 \\
5 & $98: 2$ & 4.34 & 1.00 & 2.59 & 1.15 \\
6 & $98: 2$ & 10.02 & 1.07 & 6.77 & 1.16 \\
& $90: 10$ & 0.58 & 1.09 & 0.69 & 1.00 \\
7 & $98: 2$ & 3.17 & 1.07 & 2.87 & 1.08 \\
8 & $98: 2$ & 1.82 & 2.41 & 1.77 & 1.11 \\
& $90: 10$ & 0.47 & 1.87 & 0.58 & 1.17 \\
9 & $90: 10$ & 7.82 & 1.30 & 7.82 & 1.30 \\
10 & $98: 2$ & 0.46 & 1.34 & 0.73 & 3.01 \\
& $90: 10$ & 0.25 & 1.20 & 0.35 & 2.23 \\
11 & $98: 2$ & 0.86 & 1.50 & 0.76 & 2.62 \\
& $90: 10$ & 0.37 & 1.35 & 0.25 & 2.12 \\
12 & $98: 2$ & 15.06 & 1.22 & 6.01 & 1.00 \\
13 & $90: 10$ & 3.78 & 1.36 & 2.08 & 1.00 \\
14 & $98: 2$ & 1.68 & 1.27 & 1.18 & 1.00 \\
& $90: 10$ & 0.50 & 1.04 & 0.30 & 1.00 \\
\hline
\end{tabular}

"Retention factor for the first eluting enantioner. "Selectivity factor.

anthryl ethanol in $90: 10(\mathrm{v} / \mathrm{v})$ hexane/2-propanol (Fig. 2). Retention factors $(k)$ for this analyte under the conditions used are small but its enantiomers are baseline resolved with separation factors of 1.55 and 2.75 on ADMPC- and CDMPCzirconia, respectively. Separation data of twelve racemic compounds are listed in Table 1. Most of the racemic compounds studied were well resolved on the two CSPs.

Retention and chiral selectivities of ADMPC-and CDMPCzirconia vary extensively with the type of chiral compounds as can be seen in Figure 3. For seven alcohols (1-7) investigated selectivity factors are in general greater on CDMPC than $\mathrm{ADMPC}$ while retention is alway's longer on $\mathrm{ADMPC}$ than CDMPC. For two bases (8.9) retention values are similar on the two columns but chiral selectivity is better on ADMPC-zirconia than on CDMPC-zirconia. For two cyclic ethers (10-11) retention is very short on both columns but selectivity of CDMPC is much greater than that for ADMPC. For two lactones and cyanide (12-14) both retention and selectivity are greater on $\mathrm{ADMPC}$ than on CDMPC. The CDMPC- and ADMPC-coated zirconia CSPs show complementary chiral recognition capability for types of the racemates studied.

The stability of the polysaccharide-zirconia columns were checked by measuring retention factor of the first eluting enantiomer of Tröger's base after passage of every 500 column volume of the eluent through the columns. There was only less than $2 \%$ decrease in retention factor of the test solute for the both columuns after 6.000 column volume. The high enantioselectivity of the zirconia CSPs may allow for the use of a shorter column for reduced analysis time and solvent consumption.

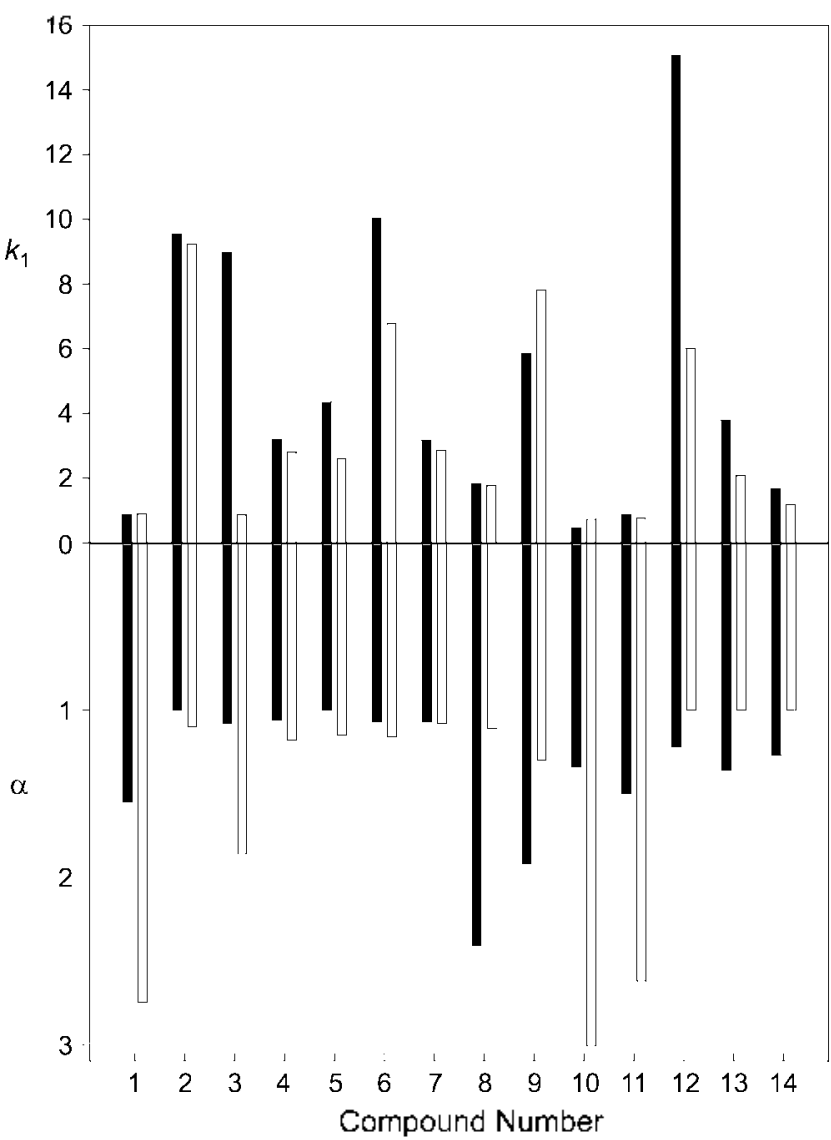

Figure 3. Comparison of retention and chiral selectivity of ADMPC- and CDMPC-zirconia. When separations were carried out at two different mobile phase compositions results for $98: 2 n$ hexane: 2-propanol were plotted. Solid bar, ADMPC; Open bar, CDMPC. Solutes: 1, trifluoroanthryl ethanol: 2 , $\alpha$-trifluoromethylbenzyl alcohol; 3, $\alpha$-methyl-1-naphthalene methanol; 4 , l-phenyl1-propanol; 5, 1-phenyl-2-propanol; 6, 3-phenyl-l-butanol; 7, 1phenyl-1-butanol: 8. Tröger's base; $9,3,5$-dinitrobenzoyl- $\alpha$-methylbenzylamine: 10, trans-stilbene oxide: 11, 4-phenyl-1,3-dioxane; 12. $;$-pheny l- $\gamma$-but rolactone; 13, $\gamma$-(2-naphthyl $)-\gamma$-buty rolactone; 14, $\alpha$-methylbenzyl cyanide.

Acknowledgment. This work was supported by the Korea Research Foundation grant (2001-015-DP0288). IWK acknowledges financial support by the Taegu University research grant (2002).

\section{References}

1. Francotte. E. In Chiral Separations: Applications and Techologt. Ahuja. S.. Ed.: American Chemical Society: Washington. 1997 . Chapter 5

2. Dingenen. J. In A Practical Approach to Chiral Separations by Liquid Clmonatography; Subramanian, G.. Ed.; VCH: New York. 1994: Chapter 6.

3. Okamoto. Y.: Kawashima. M.: Yamamoto. K.: Hatada. K. Chem. Lett. 1984. 739 .

4. Okamoto. Y: Kawashima. M: Hatada. K. J. Ant Chent. Soc. 1984. 106,5357 .

5. Okamoto. Y.: Kawashima, M.: Hatada, K. J. Chomatog: 1986. 363.173.

6. Okamoto. Y: Yashima. E. Angew: Chem. hut Ed. 1998.37. 1020. 
7. Okamoto. Y.: Kaida. Y: Aburatani. R: Hatada. K. In Chiral Separations by Liquid Chromatograply: Ahuja. S. Ed.: ACS Symposium Series 471, American Chemical Society: Washington. DC. 1991: pp 101-113.

8. Kirkland. J. I. wan Straten. M. A.: Claessans, H. A. J. Chromatogr: 1995.691,3

9. Nawrocki. J.: Dunlap. C. J.: Carr, P. W: Blackwell, J. A Biotechol. Prog. 1994. 10.561.

10. Jackson. P. T.: Carr. P. W. Chemtech. Oct. 29. 1998.

11. Castells. C. B.: Carr. P. W. Anal. Chem. 1999. 71, 3013.

12. Castells. C. B.: Carr P. W. J. Chromatogr. 2000. 904. 17

13. Park. I. H.; Ryu, J. K.: Park, J. K.: MeNeff. C. V.: Carr. P. W. Chomatographia 2001. 53.405.
14. Park, S. Y.: Park. J. K.: Park. J. H.: McNeff. C. V: Carr, P. W Microchem. J. 2001. 70. 179.

15. Hôr ₹ath. C. G.: Preiss. B. A.: Linsky. S. R. Anat Chem. 1967. 39. 1422.

16. Scott. R. P. W.: Kucera, P. J. Chrontatogr: 1976. 125, 251.

17. Ishii. D. In Introduction to Microscale High-Perforntance Liquid Chronatograpln: Ishii. D.. Ed.: VCH: Weinheim. 1988: Chapter 1

18. Okamoto. Y.: Aburatani. R.: Fukumoto. T.: Hatada. K. Chent Lett. 1987. 1857.

19. Koller, H.: Rimbock. K. H.: Mannschreck, A. J. Chrontatogr: 1983. 282,89 